\title{
Constructivism and Ecological Thought: A Critical Discussion on the Prospects for a 'Greening' of IR Theory
}

\author{
Sebastian MASLOW and Ayako NAKAMURA \\ Graduate School of Information Sciences (GSIS), Tohoku University, Japan
}

Received January 16, 2008; final version accepted January 29, 2008

\begin{abstract}
The ecological crisis, most famously represented by the issues of global warming, stepped up the political agenda of policy-makers in the domestic and international arenas. Environmental degradation, such as transboundary pollution, states a challenge to the traditional thinking of democracy and sovereignty. In arguing that the environment is underrepresented in IR theory due to the notorious anthropocentric approach of the old paradigm of rationalism, we discuss prospects for a 'greening' of IR. Against this background, we attempt to discuss aspects of green political thought (GPT) in the context of IR. Here, we focus on the work of Robyn Eckersley, who argues for a re-invention of the liberal democratic state into an ecological democracy and thus for a 'greening' of the state within and outside the boundaries of statehood. 'Greening' here, we argue, requires a theoretical approach which takes identities and interests seriously. It is here that we base our discussion on the work of Alexander Wendt, who developed constructivism into a systematic theory in IR. We try to bring Wendt's and Eckersley's thought together and to offer some answers for the state of the current ecological crisis. Against this background we argue that nature is a paramount non-constructible structure and introduce the notion of ecocentrism. Thus, we argue for a rethinking of actors' behavior within nature as a structure. It is in this context that we apply constructivism, because it offers a feasible theoretical approach for a 'greening' of states' identities and interests and thus to develop approaches toward the solution of the ecological crisis faced by the international society.
\end{abstract}

KEYWORDS: A. Wendt, Constructivism, Ecological Governance, Green Political Thought (GPT), R. Eckersley

\section{Introduction}

On July 16, 1969 Apollo 11 journeyed to the moon on board the astronauts Edwin Aldrin, Michael Collins and Neil Armstrong. The pictures Apollo 11 sent back to earth showed a fragile solitary blue planet. The image of 'Spaceship Earth' evolved into a symbol for the interconnectedness of a world which when looked upon from space was a planet with one common atmosphere, shared oceans and most importantly no borders. This was the environment as seen by the three astronauts of Apollo 11. 'Spaceship Earth' became a synonym for a shared environmental consciousness.

As fragile and interconnected as the earth appears when looked upon from space, the situation on the ground presents itself in more complicated ways. Invisible borders divide the planet into a political puzzle consisting of small, medium and large states. The overall picture is of an international system in which anarchy is the ordering principle. The notion of anarchy represents the defining parameter for rationalism, which has been the long-time dominating paradigm of International Relations theory (hence IR). Members of the rationalist school consisting of neo-realists and neo-liberals perceived the world as Hobbesian or Lockean respectively. Thus, the academic cleavage arose from the question of the prospect of cooperation in a self-help world. Here, regardless of the academic stance, theory departures from the determining notion of the structure of anarchy, in which selfish states adjusted their behavior to the structure in order to realize their highest interest of survival, through or without cooperation in the forms of international organizations or regimes. Nature, in the form of environmental concerns, within this theoretical setting disappeared behind the notion of anarchy. At the moment the environment appeared on the map it was only discussed in terms of energy and resource problems and thus was reduced to a passive object of state practice. Garrett Hardins (1968) Tragedy of the Commons illustrates well how the environment is raped and exploited in an anarchic world order in which the securing of resources is essential for the survival of selfish states.

However, enhanced interdependence in a globalized world economy with its growing governance structures challenged the bleak neo-realist worldview. Globalization - the global flow of people, goods, money and informationis not a non-state process, yet forces states to engage in intensive interaction. It is here that the old paradigm of IR faces new challenger, among which constructivism in its various appearances has to be considered the most serious contender.

Peter Haas argues that globalization means not only mobilization of people, goods, money, and information, but also the globalization of environmental externalities (1999: 103). Globalization in general and globalization of environmental externalities in particular (e.g. transboundary pollution) highlight what Friedrich Kratochwil refers to as "the subsequent subversion of the foundational distinction between 'internal' and 'external' arenas" (2007: 266). Environmental problems ignore national borders. The categories of domestic and international as the classical 
boundaries of theoretical thought in IR vanish. It is here, that the complexity of globalized problems evolve new challenges, addressed by growing networks of actors seeking new spaces in an emerging "world society" (ibid.). New networks and the complexity of global problems demand new forms of governance. New networks are not composed by states exclusively but by a broad number of non-state actors. It is here, where the emergence of a public sphere beyond national borders takes place.

The ecological crisis witnessed today offers a challenge to the traditional view of democracy and sovereignty. Although the environment climbs up the political agenda inside and outside the state, a systematic attempt towards the environment beyond the classical boundaries of IR is yet to come.

With this essay we hope to contribute to the argument of a 'greening' of the liberal democratic state as laid out by Robyn Eckersley. In doing so, we argue that a 'greening' takes place on the actor level and requires, thus, a theory which takes identity and interest formation seriously. Our approach therefore focuses on the theoretical paradigm of constructivism. Constructivism explains how actors develop 'images' about the 'self' and the 'other' through social interaction and thus turns the structure-process notion of rationalism upside-down. Moreover, we argue that nature and therefore the ecological crisis present material forces which force actors to adjust their behavior. Here, we accept the central notion of rationalism and accept the existence of a stable structure. This structure, however, is not the anarchic international system.

We will proceed at first to scrutinize the theoretical paradigm of constructivism by discussing the work of Alexander Wendt. In a second step, we then offer a discussion of Robyn Eckersley's work and provide a diagnosis of her claim of a 'green state.' We then try to bring Wendt's and Ecklersley's thought together to offer some answers for the state of the current ecological crisis and some theoretical insights to address this crisis. Against this background we then argue that nature is a paramount non-constructible structure and introduce the notion of eco-centrism. Based on this description we develop the thought of the existence of a 'green anarchy' as a fourth image and argue for a rethinking of actors' behavior within nature as a structure. Therefore, to stress the notion of a life within nature rather than nature vis$\grave{a}$-vis the human world, we argue for the use of constructivism. Constructivism is the theoretical notion which best highlights the importance of identities and interests.

\section{Wendt's Constructivism ${ }^{1}$-A Theoretical Overview}

In this section of the essay we attempt to lay out the core assumptions of the constructivist paradigm as developed by one of the main thinkers of this school in IR theory, Alexander Wendt. Through our encounter with Wendt's constructivism as presented in his numerous papers and his groundbreaking 1999 book we try to dissect the core notions of his thought. By scrutinizing this particular constructivist notion, we hope to provide one feasible steppingstone to embed ecological thought in IR theory. Needless to say that Wendt's constructivism does in no way present the only theoretical framework for an attempt to bring in the concept of nature in the form of ecological thought to IR. However, it is Wendt's notion of developing constructivism as a full fledged social theory in IR that makes it a theory of choice in this context. It provides a more stable ground for a critical theoretical discussion.

The constructivist paradigm entered the stage of international theory during the second half of the 1980s cutting across the traditional boundaries of theory, which divided rationalism and reflectivism, as well as neo-realism and neo-liberalism from each other. Questioning the old-paradigms of international relations as represented by the microeconomic and rational-choice theory orientated schools of realism and liberalism, constructivism attempts a reconceptualization of the discipline through the introduction of social theory to the field ${ }^{2}$. Katzenstein, Keohane and Krasner (1998) argue that the end of the Cold War was a catalyst for broad changes in the field of IR theory. New issues entered the field which not only provided new challenges for the realists and liberals but which also provided space for "cultural and sociological perspectives" in IR (670). In fact, as shown by their outstanding analysis of the major debates in the discipline which occurred during and after the Cold-War period, the traditional "grand theoretical orientations" 3 in IR are now supplemented by constructivism. The basic line of debate today thus runs through the rationalist and constructivist camps, which in the words of Katzenstein et al. "provide the major points of contestation for international relations scholarship" (1998: 646).

Moreover, in their analysis of the major debates in the field, Katzenstein et al. provide a summary of the constructivist thought which provides us an excellent orientation point for our further discussion of this branch of theory in IR. Therefore, we will quote them at length:

Constructivists seek to understand how preferences are formed and knowledge is generated, prior to the exercise of instrumental rationality. Constructivism analyzes discourses and practices that continuously recreate what rationalists refer to as common knowledge. Constructivists do not emphasize misperception: cognitive or emotional biases that distort rationality and can be corrected through the analysis of new information. They are more interested in the collective processes that students of social psychology have identified. Constructivists focus on discursive and social practices that define the identity of actors and the normative order within which they make their moves. We can think of these processes in two different ways: in terms of ideas about case-effect relations and regulatory norms or as more or less contested processes of identity formation (1998: 681-2). 
To locate constructivism in the field of IR theory it is worth keeping this excellent summary in mind. The main line dividing rationalism and constructivism in IR therefore can be summarized as follows: "The core of the constructivist project is to explicate variations in preferences, available strategies, and the nature of the players, across space and time" (ibid.: 682). Rationalism, on the other side, attempts to "explain strategies, given preferences, information, and common knowledge" (ibid.: 682, emphasis added by the authors). Based on this general outline of the constructivist notion, we will now outline Wendt's constructivism, which in parts reflects the above summarized core aspects.

It was Alexander Wendt, who set out to develop the notion of a 'socialized' theory of international relations. Wendt's work represents not only a major assault on the old paradigm of international relations, but "provided one of the most sophisticated and hard-hitting constructivist critiques of structural realism" (Copeland 2006: 1).

In his attack on the theoretical mainstream, Wendt argues that (neo)-realists are wrong: the international system of world politics is not a self-help system, but a realm created and recreated in a process of interaction. Therefore, anarchy is not, as Kenneth Waltz ${ }^{4}$ wants us to believe, a static 'image,' but something which changes as actors change. Wendt's core argument here is that identities are not given but developed and transformed through the process of interaction. Wendt says: "[c]onstructivists are interested in the construction of identities and interests and, as such, take a more sociological than economic approach to systemic theory" (1994: 385). The "identity move," as Maja Zehfuss terms this argument (2002: 39), distinguishes Wendt's constructivism from the mainstream of international theory associated with rationalism (cf. Katzenstein, Keohane and Krasner 1998).

Among the various forms of constructivism, which developed since the paradigm entered international theory ${ }^{5}$, Wendt embraces a form he refers to as moderate, i.e. a constructivism which receives strong influence from structurationist and symbolic interactionist sociology (Wendt 1999: 1). Katzenstein et al. (1998) divide constructivist research into three clusters: conventional, critical, and postmodern. According to this cluster of constructivist research programs, Wendt's constructivism falls into the first cluster. Here we will only very briefly summarize some ideas of the postmodern branch, because we will outline some aspects of the critical constructivist notion in our discussion of Eckersley's work in the next section of this paper, and the conventional cluster is mostly concurrent with Wendt's constructivism. The postmodern cluster is mentioned by Wendt as well as by Katzenstein et al. Although all theoretical branches share a basic understanding of the importance of discourse, postmodern constructivism in contrast to its conventional and critical comrades rejects an engagement in a debate with rationalism per se (Wendt, instead, emphasizes his willingness to engage in dialog with rationalism, as we will see later). Postmodern constructivists believe that engaging in dialog with the rationalist camp will bring in "rationalism and positivism through the backdoor" (Katzenstein et al. 1998: 677). Based on this reluctant stance, postmodern constructivists insist that knowledge is not based on stable ground, but reflects power relations, which postmodernists in this context set out to unmask through the analysis of all forms of communication, such as language. This perpetually existing problem raises doubts in the rest of the social science world. Postmodernists are often considered outsiders because postmodern constructivism clearly "risks becoming self-referential and disengaged from the world" (ibid.: 678).

The conventionalist Wendt bases his approach towards a "social theory of IR" on the emphasis of intersubjectivity in the process of identity-formation. This basic notion is laid out in his 1999 work which represents a change from Wendt's earlier conception of constructivism in international theory (cf. Zehfuss 2002: 39). An earlier definition of constructivism by Wendt reads as follows:

Constructivism is a structural theory of the international system that makes the following core claims: (1)

states are the principal units of analysis for international political theory; (2) the key structures in the states system are intersubjective, rather than material; and (3) state identities and interests are in important part constructed by these social structures, rather than given exogenously to the system by human nature or domestic politics (1994: 385).

As becomes clear from this definition, Wendt's constructivism embraces key rationalist notions, such as the statecentrism and the importance of anarchy in conceptualizing the international system (Wendt 1995: 72). Resulting from this basic assumptions, Wendt designed his constructivism as a theory to bridge the divide between neo-realism and neo-liberalism and, "by extension," between rationalism and reflectivism (Wendt 1992: 394). By adopting a systematic theory approach of scientific realism, as laid out in Social Theory of International Politics, Wendt claims for his moderate constructivism the role of a "via media" between these academic cleavages (1999: 47).

In this notion of constructivism as a "via media" Wendt does not neglect the existence of material forces per se, but he questions their influence on identity-formation, which to him is determined by process. In short, it is process that shapes the identity of actors and not structure. Therefore, process dominates structure, not vise versa, as (neo)-realists want us to believe. Thus, anarchy is subject to process, or "anarchy is what states make of it." As Wendt states:

self-help and power politics do not follow either logically or causally from anarchy and that if today we find ourselves in a self-help world, this is due to process, not structure. There is no "logic" of anarchy apart from the practices that create and instantiate one structure of identities and interests rather than another; structure has no existence or causal powers apart from process. Self-help and power politics are institutions, not essential features of anarchy. Anarchy is what states make of it (1992: 394-5, emphasis in the original).

The grounding of constructivism on the notion of intersubjectivity thus represents a fundamental difference in terms of how constructivism theorizes "structure." Wendt defines social structures in this context "by shared understandings, 
expectations, or knowledge," which "constitute the actors in a situation and the nature of their relationships, whether cooperative or conflictual" (Wendt 1995: 73). Further, Wendt argues, these social structures include material resources and that social structures exist, "not in actors' heads nor in material capabilities, but in practices. Social structure exists only in process" (ibid.: 74). Elsewhere, Wendt explains that "intersubjective structures give meaning to material ones, and it is in terms of meanings that actors act" (1994: 389). This powerful notion is paraphrased by Wendt in the simple argument that " $[\mathrm{t}]$ he Cold War was a structure of shared knowledge that governed great power relations for forty years, but once they stopped acting on this basis, it was 'over'" (1995: 74).

Influenced by Onuf ${ }^{6}$, Wendt assumes that "all theories of international relations are based on social theories of the relationship between agency, process, and social structure" (Wendt 1992: 422).

This constructivist paradigm consists of two basic principles: First, an action of any kind refers to an object, and the actions are based on the meanings that actors associate with the object. The second principle is that meaning arises from interaction, here between two actors (Wendt 1992: 396-7, 403). Therefore, the concept of 'meaning' is of central significance for Wendt.

Once more, it is intersubjectivity, which constructs international politics. This intersubjectivity influences the behavior of actors. Crucial to this notion is, however, that this intersubjectivity is constituted by 'collective meaning,' a key principle of constructivism. Speaking with Wendt "[i]t is collective meanings that constitute the structures which organize our actions" (1992: 397). Wendt's 'identity move' assumes that actors acquire identities, in order to "participate in collective meaning" (ibid.: 397). Identity is here defined as "relatively stable, role-specific understandings and expectations about self" (ibid.; see also Wendt 1994: 385). More precisely, Wendt argues that identities are the "property of international actors that generates motivational and behavioral dispositions," which means that identities are "rooted in an actor's self-understandings" (1999: 224; see also 1992: 398). Constituted by external and internal structures, Wendt distinguishes between four types of identity: (1) personal or corporate, (2) type, (3) role, and (4) collective (Wendt 1999: 224; see also Wendt 1994: 385).

Whatever type of identity we refer to, "[i]dentities are the basis of interests," which are defined in process of defining situations (Wendt 1992: 398; 1994: 385). An institution, like the one self-help represents for the structure of anarchy in the international realm, is defined by Wendt as a "relatively stable set or 'structure' of identities and interests" (1992: 399). Wendt argues, that these "specific cultural forms," regardless of whether their come in the form of norms, rules, conventions, or institutions, are constituted by "common knowledge," which for Wendt means the same as "intersubjective understanding" (1999: 159-160). The notion of common knowledge is significant, since it embodies the problematique of "distribution of knowledge" and thus directly relates to what Peter Haas developed under the concept of "epistemic communities" (1989, 1999; see third section of this paper) for the issue area of environmental cooperation and regime-formation and the problem of discourse theory, as analyzed by Robyn Eckersley (2004) or John Dryzek (1993, 1999, inter alia).

How do these parts then relate to each other? Wendt's central question of what it is that constitutes ${ }^{7}$ anarchy, if not material force, results in the argument that through interaction different forms of anarchy are constructed. To be more precise, Wendt distinguishes between three cultures of anarchy: (1) a Hobbesian culture, in which states cast each other in the role of enemies, (2) a Lockean culture, in which states see each other as rivals, and (3) a Kantian culture, in which states cast each other as friends (1999: 258, 260-2, 279-80, 298-9, see Fig. 1).

\begin{tabular}{|lll|}
\hline Perception of the 'other' & Security system & Culture of anarchy \\
\hline enemy & competitive & Hobbesian \\
rival & individualistic $\longrightarrow$ Lockean \\
friend & cooperative & Kantian \\
\hline
\end{tabular}

Source: Wendt (1992, 1999)

Fig. 1. Wendt's three cultures of anarchy.

The form of anarchy is determined by the perception of security each actor possesses about the other, i.e. what its identity is in relation to the 'other.' Wendt states:

Processes of identity-formation under anarchy are concerned first and foremost with the preservation of "security" of the self. Concepts of security therefore in the context to which and the manner in which the self is identified cognitively with the other, and, I want to suggest, it is upon this cognitive variation that the meaning of anarchy and the distribution of power depends (1992: 399-400). 
Wendt's three forms of anarchy based on the cognition of security by the self in relation to the other are paralleled by three forms of security system: (1) competitive, (2), individualistic, and (3) cooperative security system (Wendt 1992: 400, see Fig. 1). Based on this categorization, Wendt (1992) concludes that "[d]epending on how well developed the collective self is, it will produce security practices that are in varying degrees altruistic or prosocial" which in effect will "make collective action less dependent on the presence of active threats and less prone to free riding" (ibid.: 401). Therefore, only in a cooperative security system, in which states have internalized norms as part of their identity, the international system is in full harmony with the logic of the constructivist paradigm. In short, Wendt argues that in a collective security system as represented by the notion of the Kantian culture, norms do truly construct states, through constructing their identities and influences (1999: 250; see also Copeland 2006: 6-7). The Hobbesian state of nature, Wendt argues, is transformed by the principle of sovereignty through "providing a social basis for the individuality and security of states" (1992: 412). Such as self-help sovereignty represents an institution, thus "it exists only in virtue of certain intersubjective understandings and expectations; there is no sovereignty without an other" (1992: 442; see also 1994: 388).

The assumption that states, involved in interaction, have conceptions of self and other, is fundamentally different from the paradigm of rationalism, thus Wendt concludes, that "anarchy and the distribution of power only have meaning for state action in virtue of the understandings and expectations that constitute institutional identities and interests" (1992: 401).

Finally, we will focus on the process of interaction through which identities are formulated. Wendt's constructivism argues that identities arise from interaction between the 'self' and 'other,' in which the interests and practices of the 'self' tend to reflect (Wendt uses the term "mirror," see 1992: 404) the interests and practices of the other. This principle of symbolic interaction thus claims that "the self is a reflection of an actor's socialization" (Wendt 1992: 404, see Fig. 2). This notion is illustrated by Wendt's Ego and Alter model (Wendt 1992: 404; 1999: 328-31). A basic assumption for interaction between Ego and Alter (or say between State A and State B) is that their identity sheet is not tabula rasa, i.e. actors have interests independent of their social context. Those are "to preserve and further their physical security, autonomy, economic well-being, and collective selfesteem" (Wendt 1999: 235-7). Framed by these pre-social conditions interaction takes place in a continuing pattern consisting of processes of signaling, interpreting, and responding. One completed process (i.e. socialization) constitutes a "social act." The first "social act" process creates certain expectations on both sides of the interaction process. A social act then constitutes intersubjective knowledge, which is pooled (collective knowledge). Once knowledge exists, practice is socialized. Through reinforcing the process of 'looping' social acts, ideas about the 'other' are established, which encourage or discourage further interaction. Through what Berger and Luckmann call "reciprocal typifications," identities and expectations can evolve into stable patterns (Wendt 1992: 405-6). Wendt summarizes this notion as follows: "[i]f states find themselves in a self-help system, this is because their practices made it that way. Changing the practices will change the intersubjective knowledge that constitutes the system" (1992: 407).

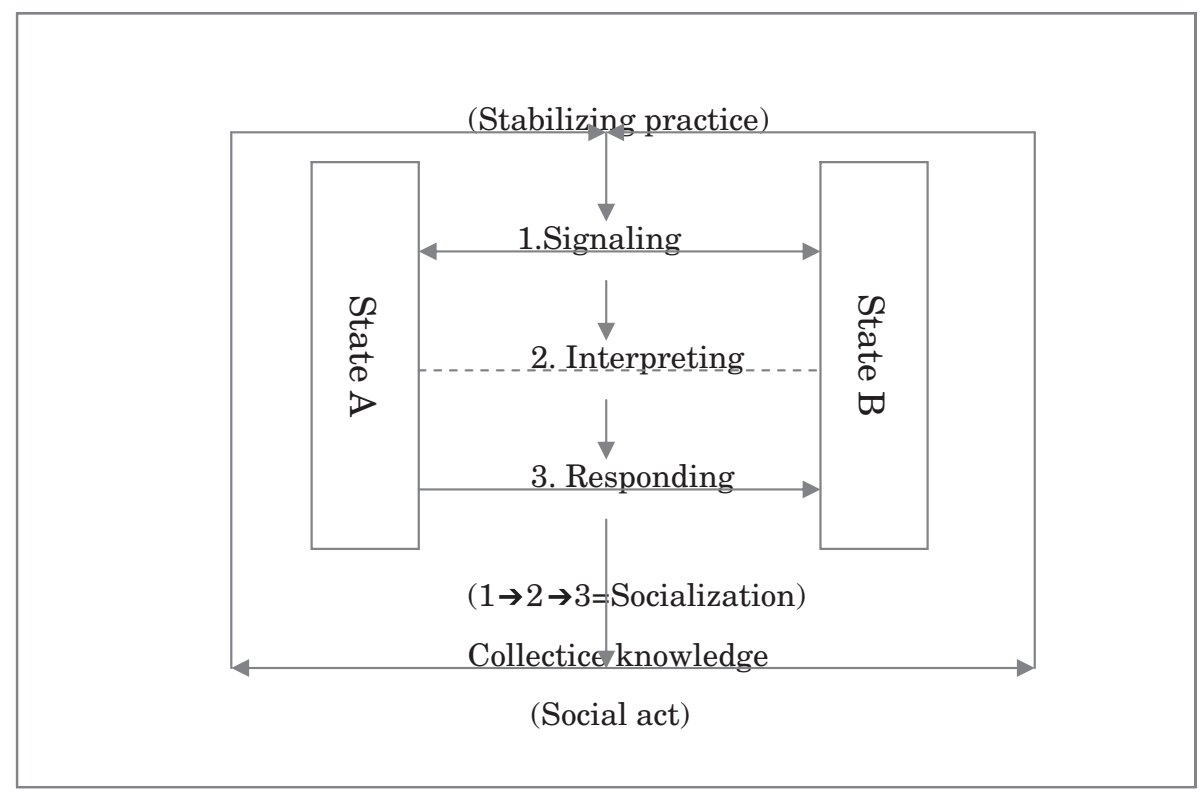

Source: Wendt 1992, 1999; compiled by the authors.

Fig. 2. Wendt's model of social interaction. 
Moreover, "institutions transform identities and interests," and the key to such "transformations is relatively stable practice" (1992: 412).

In summary, the essential aspect of what we have described above is the question of what produces structures. The answer offered by Wendt is practice. It is practice that reproduces and transforms structure. Structures, as far as Wendt's constructivism as a critique of Waltz's neo-realism is concerned, therefore, are "not static background conditions for collective identity formation" (Wendt 1995: 389). Practices have causal impacts. Identities, as we have seen above, are formed by systematic processes, defined as "dynamics in the external context of state action" (ibid.). A connecting point for Eckersley's notion of a 'greening' of the liberal democratic state in the international arena (third section) is the systematic process of identity formation. The two processes which form identities are, thus, the rise of interdependence in the international arena (e.g. through environmental multilateralism), and what Wendt refers to as the emergence of a "common Other," which can be an aggressor or a more abstract threat such as "ecological collapse" (Wendt 1994: 389). Therefore, if rationalists argue that the international system is a structure of anarchy, then Wendt answers this point by claiming that it is "the intersubjective knowledge that constitutes competitive identities and interests" and these are "constructed every day by processes of 'social will formation'” (Wendt 1992: 410). In short then, anarchy is what states make of it.

Identity formation is a feasible framework for our description of the ecological thought of Robyn Eckersley, who, albeit from the perspective of a critical constructivism, bases parts of her notion of a green state on the ideas of Wendt.

\section{Bringing in the Environment-Green Political Thought and Constructivism}

In the following section of this essay we attempt to analyze aspects of the relationship between green political thought and the constructivist paradigm, as outlined above. Here, we are mainly interested in the question of a constructivist explanation for the issue of ecological degradation in the field of international relations and prospects for constructivist solutions in addressing these problems.

A feasible stepping-stone between green political thought and constructivism can be found in the scholarship of Robyn Eckersley. Eckersley, although not well known in the Japanese academia, is a leading scholar in the field of green political thought, who only recently set out to explore the possibilities for the 'greening' of international theory (inter alia, 2004, 2007a). The cornerstone of this attempt is her claim for a reconceptualization of the liberal democratic constitutional order towards an 'ecological democratic state.' In attempting a 'green state,' Eckersley explores the possibilities of a 'greening of sovereignty' with respect to the internal as well as external arena of the state. In the following section, we will outline Eckersley's 'green state' argument.

\subsection{From a Liberal Democratic State to an Ecological Democracy-The Green State}

The ecological crisis is mainly associated with the development of states. Thus, in order to solve environmental problems many green political theorists, especially those associated with the 'deep ecologist' camp, argue that abolishing the state is an unavoidable step in solving the ecological crisis. Eckersley dissociates herself from those views. For her, the state plays a central role in addressing the environmental problems. In her view, the crucial task in solving ecological problems is to transform the state along more ecologically sustainable lines (2004: 2, 6). Therefore, the argument for a green state is a case based on a state-centrist view. In doing so, Eckersley argues against the ecological branch of green political thought but allies herself with the social constructivist notion of Wendt, who placed himself with his state-centrist worldview between neo-realism and neo-liberalism. For Eckersley, the logic behind the ecological crisis of our times bears a different reading: if it is states that cause environmental problems then we need to find ways to transform the institution of statehood. Eckersley's approach to a green democratic theory attempts to reinvent the state as an actor in politics. Here she argues that a green theory of any kind needs to demand a proper role for states within and outside their boundaries; thus, to look at current structures of governance, which are part of what causes ecological problems, is an all too obvious starting-point for theory-building. Bringing her state-centrist approach to a point, Eckersley argues: "[t]hus, like or not, those concerned about ecological destruction must content with existing institutions and, where possible, seek to 'rebuild the ship while still at sea" (2004: 5). Within her conceptual framework the state would remain a "crucial 'node' in any future network of global ecological governance" (2004: 5). The notion resulting from this state-centrist stance is a normative theory of the state, which seeks a "proper role of the nation-state vis-à-vis its own society and territory, the society of states, global civil society, and the global environment" (2004: 1).

The green-state Eckersley attempts is "a democratic state whose regulatory ideals and democratic procedures are informed by ecological democracy rather than liberal democracy," and which seeks its fundaments in an "immanent (ecological) critique" (2004: 2, emphasis in the original). Therefore, the green-state notion is a claim for a "postliberal" democratic order, which will emerge most likely from the environmental and broader green movements. The hope which Eckersley connects with this notion is that a green democratic state might be more capable of evolving an "ecologically responsible statehood" (2004: 2).

The green-state notion is a far-reaching model, which demands a radical transformation of the liberal democratic 
state. Once a state develops along these lines, it ought to be able to attain a new role, that of an "ecological steward and facilitator of transboundary democracy rather than a selfish actor jealously protecting its territory and ignoring or discounting the needs of foreign lands" (Eckersley 2004: 3). Clearly, Eckersley attaches to these new roles radical challenges to the traditional concepts of nation and sovereignty (ibid.). ${ }^{8}$

\subsection{The Theoretical Framework of "Critical Political Ecology"}

In her attempt to lay out a constitutional design for a green state, Eckersley develops the notion of a 'green political ecology' as a theoretical framework. Here, a critical political ecology draws heavily on the tradition of critical theory, especially that of the Frankfurt School, which Eckersley attempts to "rehabilitate" through her approach to green political theory. The cornerstone of the critical political ecology notion is to extend the moral community to include both the human and non-human worlds, which ultimately turns the 'green state' into a "more legitimate" project than its liberal counterpart (Eckersley 2004: 140). This approach adapts as its theoretical basis a concept, which Eckersley terms a "critical constructivism." 9 This concept paraphrases the insights of social constructivism in the following way:

all knowledge reflects particular social purposes, values, interests, and story lines, and this insight extends as

much to our understanding of the so-called natural world as it does to the social world (Eckersley 2004: 9).

Behind the notion of expanding the moral community lies Eckersley's concept of an ecocentrism, in which she develops a 'reality,' in which "the world is an intrinsically dynamic, interconnected web of relations in which there are no absolutely discrete entities and no absolute dividing lines between the living and the nonliving, the animate and the inanimate, or the human and the nonhuman" (Eckersley 1992: 49). Ultimately, ecocentrism argues for an extension of autonomy "to a broader and more encompassing pattern of layered interrelationships that extend beyond personal and societal relations to include relations with the rest of the biotic community" (ibid.: 55; see also Dryzek 2000: 145-147).

The notion of ecocentrism in application to mainstream international theory and social constructivism would demand a radical rethinking of the concept of self-determination. Here, it does not matter whether we talk about anarchy as the dominant structure or the individual as the agent constructing anarchy as the focus of our analysis. Both viewpoints are in the end anthropocentric and thus tend to marginalize nature. Although Eckersley does not refer to nature as a structure, the ecocentric notion demands ultimately a concept which perceives nature as a transcendent structure.

Essential for the notion of critical political ecology then is that it seeks a broader understanding of the concepts of social and environmental justice within the context of communicative justice (Eckersley 2004: 10).

Last but not least, a hope connected to the constitutional design of a green democratic state is the emergence of a "green public sphere" as an extension of Habermas's concept of a bourgeois public sphere. Here, a green public sphere functions as a space for the provision of complete environmental information, mechanisms for contestation, participation, and access to environmental justice. A green public sphere, based on Douglas Torgerson, is an "open series of green discourses made up of fluid, diverse, and changing connections and sites if environmental concern and discourse" (2004: 156-7). Eckersley hopes that in promoting the development of such a sphere the possibility that a "reflexive learning of both the state and civil society" will increase (ibid.: 140).

Thus, in arguing that a green state will most likely emerge from the environmental and green movements, Eckersley emphasises the importance of political discourse:

green political theorists and green activists should become less instrumental in their approach to politics and more attuned to the value of politics - or open political dialogue/conversation-as an end in itself. In effect, while green movement could possibly survive without debate, the end of debate would spell the end of the green public sphere (2004: 157).

An essential aspect of 'greening' the state is to bring in groups who are subject to bias and marginalized in contemporary political dialog. Ultimately, empowerment of marginalized groups becomes essential. In Eckersley's interpretation one approach of initiating political mobilization is through coalition building. A green state attempts the introduction of strategies of "empowerment of all those who have been marginalized in the making of decisions involving ecological risks” (2004: 157).

In fact, the concept of the public sphere is crucial for Eckersley's concept of an ecological democracy in terms of how to green the liberal democratic state. Her approach of greening the democratic state is based in large part on a critical discussion of Habermas's concept of discursive democracy. To lay out Eckersley's dialog with Habermas's thought goes beyond the scope of this essay. Eckersley's main critique of Habermas's concept of the public sphere can be summarized with the notion that Habermas does not provide detailed thoughts on how to achieve a flourishing public sphere. Eckersley's notion of an extension of the moral community and her emphasis on environmental justice in her critique of Habermas then reads as follows: "Habermas's account of moral reasoning is not moral enough while his acceptance of pragmatic compromise is too complacent and uncritical" (2004: 165). Thus, Eckersley attempts to move beyond Habermas's "uncritical acceptance of a liberal political culture" (ibid.: 166). For Eckersley Habermas's notion of discursive democracy is characterized by a "pragmatic reasoning" which "predominates over moral and ethical reasoning in the policy making and legislative process" (ibid.: 164). Her theoretical notion of a critical political ecology sets out to counter Habermas's discursive democracy in arguing that considering the inclusion of other "sort[s] of beings beyond the human realm" in terms of representation and consideration in dialog is a "matter of justice" (ibid.: 166). Thus, Eckersley argues that "[t]reating these questions merely as ethical questions necessarily leaves the fate of 
future generations and nonhuman others to the uncertain motivations and inclinations of those who happen to be present in any given dialogue" (ibid.: 166). After all, however, arguing from a statist perspective Eckersley affirms the positive role of the public sphere in the context of greening the democratic state. By referring to the work of neoHabermasians such as John Dryzek and Iris Young, Eckersley argues that the state should be concerned with active intervention in society and economy "in order to promote social justice and environmental justice" (ibid.: 161) and to make the state more responsive to critical feedback from civil society via the public sphere. Tensions between state and society, thus, are not negative. The problem we must address here is "to explore how they might be played out in more creative ways, particularly for those groups that have historically been excluded or marginalized in the process of policy making" (ibid:: 164).

Based on this broad encounter with discursive theory Eckersley then shapes her argument for an ecological democracy. It is worth quoting her thought at length here:

Our ambit claim for ecological democracy is one that, ideally, asks participants in any discursive forum to examine proposed norms from the perspective all significantly affected others, citizens or noncitizens, the living and the not-yet-born, human and nonhuman. The quest is to develop procedures and decision rules that might encourage participants to at least strive to adopt "the moral point of view" rather then merely seek to

further their own narrowly conceived interests by strategic bargaining (2004: 165).

This ambitious claim embodies Eckersley's notion of an ecocentrism as outlined above. Finally, we shall take notice of Eckersley's self-limitation in arguing for the greening of the liberal democratic state. The green state Eckersley argues for is a project that will never reach its final point. In fact, she argues that this project must be understood as an "ongoing process of finding ways of extending recognition, representation, and participation to promote environmental protection and environmental justice" (2004: 169). This process takes place within and outside the boundaries of traditional statehood. In the next part we will focus on the state-external arena by trying to link some of the above outlined aspects of Wendt's constructivism with Eckersley's notion of a green state embodied in a critical constructivist framework. In addition to this conventional-critical constructivist liaison we will emphasize further aspects to broaden this green theoretical discussion.

\subsection{Bringing In Nature-Wendt's Constructivism and the Environmental Challenge}

In her attempt to green the liberal democratic state Eckersley identifies three main obstacles. This essay will focus primarily on the first because of its relation to the external realm of the state, i.e. its linkage to the field of international theory and therefore to our central question formulated above. The three main obstacles are as follows (2004: 14): (1) the anarchic character of the international society, (2) the expanding process of globalization, and (3) the democratic deficits of the liberal democratic state.

Against the background of these obstacles, Eckersley argues that giving, for instance, the ecological crisis of our time, states are indeed able to transform as governance structures to address these challenges. However, any transformation must be focused on "deepening the democratic accountability and responsiveness of states to their citizen's environmental concerns while also extending democratic accountability to the environmental concerns of transnational civil society, intergovernmental organizations and the society as states in general" (Eckersley 2004: 14-5).

Let us now focus on the relationship between constructivism and Eckersley's notion of a green state.

The relationship evolves around the question of under which conditions a green state can develop in the international realm. 'Greening' here begins with cooperation. Eckersley argues that the emergence of an enhanced environmental multilateralism is capable of transforming the "logics of international anarchy" (2004: 15). Here, Wendt's work provides useful insights into the question of how different structures can produce different roles or identities (ex. the role of an environmental leader) and how these structures determine the relationship between actors. As we have already noted in the second section of this paper, Wendt distinguishes between three cultures of anarchy based on states' perception of security in relation to other states (see Fig. 1). Thus, if states consider the condition of security as Hobbesian, i.e. they fear being stabbed in the back, cooperation is most unlikely. If states perceive each other as rivals, as is the case in Wendt's Lockean culture of anarchy, cooperation becomes more likely, but would still be based on the notion of self-interest. Only in a Kantian culture of anarchy then, states recognize each other as friends and cooperate around shared and internalized understandings (collective knowledge) (Wendt 1999: 258, 260-2, 279-80, 298-9); and, as Eckersley adds, probably on grounds of moral/ethical reasoning (2004: 44). Thus, environmental cooperation will most likely emerge in what Wendt terms a "cooperative security system" (1992: 400). Here, an environmental threat would not only be perceived as a security threat to oneself but also to the other. This understanding could be referred to as a holistic approach to the ecological security ${ }^{10}$ notion of the rationalist camp, especially neo-realists. Environmental cooperation in a Kantian culture could than also be regarded as the result of an enhanced and probably more institutionalized pattern of an open discursive process (Eckersley 2004: 45).

The constructivist notion as outlined by Wendt and others, explains effectively which processes led to the emergence of norms and in general how actors change their interests and identities. Here, for the notion of the 'greening' of liberal democratic states, Wendt's understanding of identity-formation through social interaction is essential, because it states that norms and rules, which emerge from this interaction, are by nature, constitutive and re-constitutive (cf. Eckersley 2004: 35). 
Focusing on the external realm of the state as marked by the rise of environmental multilateralism, the notion of a critical constructivism enables us, argues Eckersley, to understand the social transformations which led to this development. However, in order to understand these developments in their entirety it is essential to bridge the "disciplinary division between international relations, domestic political studies of state/society relations, and the sociology of globalization” (2004: 34).

Applying Wendt's model of the three cultures of anarchy, ecological degradation will most likely occur in a Hobbesian culture, because of the absence of cooperation due to the overwhelming force of self-interest. Environmental cooperation then is mainly regarded as altruistic. Thus, doing nothing serves probably more the national interest than undertaking unilateral action to protect the environment from degradation. Ultimately, Eckersley argues, realists may "be accused of being complicit in the perpetuation of such exploitation" (2004: 24). Although neo-liberals contributed much to the research on regime building and emergence of international environmental governance in the field of environmental affairs, it does not, argues Eckersley, explain the underlying social transformations which are constitutive for regimes in a constructivist sense. Thus, environmental cooperation in a neo-liberal institutionalist worldview must first pass the "utilitarian calculation" test, before they can be materialized. This, Eckersley argues, can only lead to the emergence of a "pale green state whose material interests and identities as calculating, strategic actors remain unaltered" (ibid.: 31 ).

The neo-realist (and to a certain extent the neo-liberal) explanation for environmental degradation is very well illustrated by Garret Hardin's influential paper The Tragedy of the Commons (1968). In short, for realists, the environment is marginalized by the rationality of anarchy.

It is here that Wendt and Eckersley's thoughts merge. If Wendt claims that "anarchy is what states make of it," then for Eckersley the "ecological crisis is what states make of it." Here, it is worth quoting Eckersley at length to frame the main points of her argumentation:

critical constructivism, (...), is able to point to the changing practice of multilateralism, which carries the potential to broaden the roles and identities of states to include that of ecological steward, replacing the traditional role of environmental exploiter (2004: 20).

In other words then, constructivism is able to highlight the path of what Eckersley terms an "enlightened ecological governance" (2004: 19), and does not block this path with arguments of an unshakeable anarchic international structure, in which an ecological crisis is justified by the 'logic' of self-help.

\section{4 'Knowing' the Facts-And some Critical Remarks}

That Eckersley's claim for a greening of the liberal democratic constitutional order within and outside the boundaries of statehood through an enhanced environmental multilateralism is not an entirely ungrounded normative undertaking but it can be based on empirical evidence. Peter Haas argues that the economic globalization has created not only transboundary and global environmental externalities but also a growing system of multilateral international governance, especially after the 1972 United Nations Conference on the Human Environment (UNCHE). From the 500 or so multilateral environmental agreements, which constitute the core of today's global environmental governance network approx. 60 per cent have been signed after 1972 (Hurrell 2006: 172).

Ultimately, what we need for greening the state are norms and rules and by extension regimes, that are constituted and that re-constitute state-identities. The essential question then is, where the loci of the inertia for the formation of regimes can be found. One answer with reference to Wendt would be that certain actor interests exist independently from interaction, such as the interest to survive. Ergo, if environmental degradation poses a threat to the higher interest of survival then cooperation, if only on the level of self-interest (here, Wendt's explanation does not contradict neoliberal institutionalism, but accounts for the processes of deeper lying social transformations) is more likely than ignoring the threat and thus to continue to 'dig our own grave.' Ultimately, then, the greening of states takes place, albeit within the conceptual framework of 'ecological security,'11 and this is in fact what we are witnessing internationally at present. Eckersley does not ignore this tendency (2004: 27). This "modest greening of the rationale of states" is not, argues Eckersley, in contrast to neo-liberals, a "self-justifying norm but rather takes its meaning from the changing constitutive discourses that underpin it" (ibid.).

That said, it is essential to ask what constitutes the action which leads to the perception of the ecological crisis as a threat to national interest and then to the construction of regimes which try to address ecological problems. At this point knowledge becomes clearly significant. Eckersley does argue that the harbinger of a green state is most likely the environmental and broader green movement (2004: 2), but the importance of the process of the 'distribution of knowledge' in the context of environmental multilateralism needs more emphasis. We argue that if environmental multilateralism is the engine for greening the state within the international arena, then knowledge is the fuel that keeps the engine running.

The importance of knowledge in the process of regime formation is explored by Peter Haas (inter alia, 1989, 1999). Looking at the growing system of environmental governance Haas argues that "[t]he norms, rules and strategies for environmental governance are no longer widely contested." In fact, "[t]hey are now enforced within a multilateral governance structure which systematically limits the role of the state" (Haas 1999: 101). The evolution of this rather novel system of global environmental governance bases mainly on two aspects: (1) the importance of science for the 
understanding of environmental problems, and therefore the significance of international scientific institutions, and (2) the transnationalization of the state, which resulted in the arena of environmental politics in a shift of the level of enforcement upward and downward, i.e. from states to international institutions and NGOs respectively (ibid.). Haas refers to this process as an international decentralization (1999: 140). In tracing the evolution of international environmental governance structures, Haas argues that ecological "epistemic communities," 12 through which the distribution of knowledge takes place, provide the basis for these governance structures. Based on this knowledge, new beliefs can be institutionalized and the formation of new regimes achieved. Haas argues that "epistemic communities" are crucial "channels through which new ideas circulate from societies to governments as well as from country to country" (Haas 1992, in Hasenclever, Mayer and Rittberger 1997: 149).

An attempt to fully present the complex notion of "epistemic communities" lies beyond the scope of this essay. Of course we are aware that the notion of "epistemic communities" in the realm of regime theory is 'only' a "weak cognitivism,' as Hasenclever, Mayer and Rittberger call it, which demands that regimes "depen[d] on actors' perception of international problems," and not for a complete alternative theory of regimes, as promoted by 'strong cognititivism' (Hasenclever, Mayer and Rittberger 1997: 137). We also admit that 'scientific' knowledge distributed by "epistemic communities" is 'filtered' (i.e. selected) and that often "epistemic communities" are part of bureaucratic apparatuses, but on the other hand, they are also producers and distributors of innovative policies (ibid.: 151), and today are important actors in the context of the climate change debate (in form of the Intergovernmental Panel on Climate Change, IPCC $)^{13}$. But if we consider the greening of the internal and external boundaries of state as an incremental process, knowledge and thus competent understanding of the complexity of the ecological crisis is essential and thus needs to be further addressed. In this sense, not knowing the ecological crisis is the same as not addressing the ecological crisis.

\subsection{Prospects for a Green Theory in IR}

What are the prospects for greening the state in international theory and thus for seeking more ecologically feasible solutions for the ecological crisis of our time? Eckersley's answer to this question is that she sees in an ecological reinvention (in the sense of an identity-formation process) of the state in the domestic and international arenas through enhanced environmental multilateralism the possibility of the emergence of a transnational state (i.e. to transnationalize democracy, and therefore an ecological democratic constitutional design). Here, Eckersley's transnationalization argument follows in part Dryzek's argument for a “transnational democracy” (Dryzek 1999). For Eckersley, this notion is made possible through overlapping structures of rule among spheres of national and international governance created by environmental multilateral agreements. This tendency is already reflected by the 1998 Convention on Access to Information, Public Participation in Decision Making and Access to Justice in Environmental Matters of the United Nations (Eckersley 2004: 192-3).

As we have seen in this discussion, Wendt's constructivism and Eckersley's notion of a 'green state' through enhanced environmental multilateralism both stress the significance and potential of cooperation. For Eckersley this cooperation based on Wendt's Lockean and Kantian culture of anarchy evolves a transnational state. In fact, here she follows Wendt, who developed a similar notion. In the context of Wendt's argument the process of social interaction engages actors (i.e. states) in a framework of "collective identification, which constitutes an important condition" for what he terms the rise of "international states" (1994: 385). With reference to Robert Cox, Wendt defines "international states" as "transnational structures of political authority that lack a single head" in contrast to $a$ "state" as a "structure of political authority that performs governance functions over people or space" (Wendt 1994: 392, emphasis in the original). Here, Wendt stresses the point that the internationalization of states in general requires two qualities: (1) the identification with certain state functions (Wendt mentions e.g. military security, and we add ecological cooperation), and (2) a "collective capacity to sanction actors who disrupt the performance of that function (1994: 392). This collective identification then results in stable practices, which hence result in an "institutionalization of collective action" (i.e. routine) (ibid., emphasis in the original; see Fig. 2). Further, Wendt emphasizes that this institutionalization will be expressed by norms, rules, and principles, which hence will "define expectations for behavior; routine discussions of collective policy; and interorganizational networks among bureaucratic agencies" (ibid.). Wendt's explanation for the emergence of 'collective security systems' provides a blueprint for Eckersley's claim for green states in the international arena. The key lies in what Wendt terms "collective identity formation." 14 Eckersley's claim for an extension of the moral community and hence the boundaries of identification (Eckersley 1992 , 2000) can be backed up by Wendt's "collective identification" move. Wendt argues: "[i]n any given situation, (...), it is the nature of identification that determines how the boundaries of the self are drawn" (Wendt 1994: 386).

It is against this theoretical background, that analyses of the steadily growing ecological governance structure, due to the numerous environmental agreements which have been signed, especially since 1972, provide reason to believe that IR is already witnessing a greening of its own; albeit, as Eckersley critically remarks, under the banner of 'ecological security' (Eckersley 2004: 27). The question in point then is how successful are current international theories in analyzing and formulating solutions for environment degradation?

Ironically, what we are witnessing today is nature setting the political agenda in the domestic and international arenas. Has the ecological crisis and the threat of irreversible changes in climate really changed our identities or are we 
only behaving as if we were ecologically interested because everyone else does? Thus, the irony is that the ecological crisis (i.e. nature) evolved into a structure of its own, in which 'material forces' are now a threat to all members of the international society (taking economic disparities in consideration then these material forces hit the poor earlier and harder, then later, the rich). In the end neo-realists are right; it is structure that shapes process. Only, we do not have nature as a structure on our theoretical map in IR. If anarchy is the third image for neo-realists, than probably we should think of nature as the paramount fourth image. Indeed, this structure exists independently from our social interaction; it is effected by our action (ex. pollution).

\section{Concluding Remarks: Toward an Eco-constructivism (or Eco-neo-realism)?}

We have tried to explain the focal points of constructivism by showing how images about the 'self' and the 'other' are developed through social interaction. We have then described some aspects of critical constructivism within the context of green political thought to show that there are, albeit idealistic, alternatives to the liberal democratic state which represents a part of the ecological crisis. We then set out to merge some of the aspects described by Wendt and Eckersley. By doing so, we argue here that constructivism (in its conventional and critical forms) is applicable to develop solutions for the ecological crisis.

At the same time, however, we argue that nature (only the concept of nature is a result of social interaction) exists independently from social interaction. This notion is consequent if we follow Eckersley's notion of an ecocentrism. Here, states' actions must be perceived as actions within nature rather than conceiving of nature as an object of action, as it is currently the case.

The argument of nature as a paramount and stable structure thus embraces key aspects of the rationalist paradigm in IR. The claim for an 'eco-neo-realism,' for instance, seems improbable, because of its lack of concern for the identity aspect, which is essential for taking the preliminary step of recognizing the environment as a structure. Therefore, we argue for a theoretic framework, which brings in the environment as a structure, but at the same time addresses the process of social interaction; because 'greening' the ego takes place on the actor level (through identity and interestformation).

We argue for an amalgamation of an ecocentric version of constructivism, an eco-constructivism, in IR, based on Eckersley's concept of a critical constructivism, which argues for an extension of the moral community by including the non-human world.

\section{Notes}

${ }^{1}$ We borrow this phrase from Maja Zehfuss's excellent chapter on Wendt (2002: 38-93), which provides at the same time a helpful overview of Wendt's work.

${ }^{2}$ For a detailed description of the rationalist-reflectivist divide in international theory from neo-liberal perspective see Robert Keohane (1988).

${ }^{3}$ With the term "general theoretical orientation" Katzenstein et al. summarize the main theoretical paradigms of IR, namely realism, Marxism, liberalism, statism, pluralism, historical institutionalism, rational choice institutionalism, and constructivism (1993: 646).

${ }^{4}$ Constituting for the paradigm of neo-realism (or structural realism) was Waltz's 1979 published influential work Theory of International Politics.

${ }^{5}$ There is no commonly agreed categorization of the various streams of thought within constructivism in IR. Broadly, Wendt distinguishes between "holist" and "materialist" lines in constructivist thought, which embody the three streams of modern, postmodern and feminist constructivism, see Wendt, 1999: 1-4. A different categorization is provided, inter alia, by Christian Reus-Smit, who divides the field into systematic, unit-level, and holistic streams of constructivism. Here Wendt belongs to the stream of systematic constructivism; see Reus-Smit (2005): 199-201; see also Wendt (1995).

${ }^{6}$ Onuf pioneered the introduction of social theory in IR theory. Broadly speaking, Onuf's constructivism claims that it is people who construct reality through action, here especially through words, or, in the words of Onuf, "speech acts" (1989). Or in borrowing Zehfuss's phrase, it is "[w]ords making the world" (2002: 153).

${ }^{7}$ The term "constitute" is further clarified in Wendt (1995): 72, footnote 6.

${ }^{8}$ For an excellent discussion of the concept of green democracy within the context of democratic theory, see Dryzek 2000: chp. 6. Dryzek agrees with Eckersley, that the current liberal democratic order is not capable enough to address the ecological crisis. He argues that liberal democracy performs insufficiently well on criteria such as negative feedback mechanisms ("the ability to generate corrective movement when natural system's equilibrium is disturbed"), coordination across problems and actors, or flexibility. Dryzek argues that most of these feedback and coordination mechanisms are dominated by pluralistic interests (ex. economic or labor); cf. Dryzek 2000: 143-4.

${ }^{9}$ For a detailed overview of critical constructivism see also Katzenstein, Keohane, and Krasner (1998), 677-8.

${ }^{10}$ For a detailed description of the concept of environmental security in adaptation to the East Asian context, see 
Haque 2001.

${ }^{11}$ See also Eckersley 2004: 224. Eckersley takes her argument of a 'greening' of the state and the international further, by discussing the prospects of an 'ecological intervention' and 'ecological defense.' Here, the question is whether the international community should be as much concerned about massacres against endangered species as it is in the case when force is perpetrated against humans. Thus, can we speak of "crimes against nature" and thus support "a new norm of ecological intervention and an international environmental court? If the international community condemns genocide, might it one day be ready to condemn ecocide?" Again, this argument follows Eckersley's claim of an extension of the moral community to include the non-human world, as outlined in her concept of an ecocentrism, see Eckersley 2007b: 293, and Eckersley 2004: chp. 8.

${ }^{12}$ Epistemic communities are defined as "networks of professionals who share common normative and causal beliefs, accept common truth-tests and are engaged in a common policy enterprise," Haas 1999: 117; see also Haas 1989: 384, here esp. footnote 20.

${ }^{13}$ For an excellent discussion on the climate change debate and the role of science in a constructivist context see Demeritt (2006).

${ }^{14}$ See especially Wendt 1994: 388-391, and the second section of this paper.

\section{REFERENCES}

Copeland, Dale C. (2006), "The constructivist challenge to structural realism," in Guzzini, Stefano and Anna Leander (ed.), Constructivism and International Relations: Alexander Wendt and his critics, London and New York: Routledge.

Demeritt, David (2006), "Science Studies, climate change and the prospects for constructivist critique," Economy and Society, 35-3: 453-479.

Dryzek, John S. (1999), "Transnational Democracy,” The Journal of Political Philosophy, 7-1: 30-51. Press.

Eckersley, Robin (1992), Environmentalism and Political Theory: Toward and Ecocentric Approach, Albany: State University of New York Press.

(2004), The Green State: Rethinking Democracy and Sovereignty, Cambridge/London: MIT Press.

(2007a), "Green Theory," in Dunne, Tim, Milja Kurki, and Steve Smith, International Relations Theory, Oxford:

Oxford University Press.

(2007b), "Ecological Intervention: Prospects and Limits," Ethics \& International Affairs, 21-3: 293-316.

Haas, Peter M. (1989), "Do Regimes Matter? Epistemic Communities and Mediterranean Pollution Control," International Organization, 43-3: 377-403.

(1999), "Social Constructivism and the evolution of multilateral environmental governance," in Prakash, Aseem and Jeffrey A. Hart (ed.), Globalization and Governance, London and New York: Routledge.

Hardin, Garrett (1968), "The Tragedy of the Commons," Science, 162: 1243-1248.

Hasenclever, Andreas, Peter Mayer, and Volker Rittberger (1997), Theories of international regimes, Cambridge: Cambridge University Press.

Haque, M. Shamsul (2001), "Environmental security in East Asia: a critical view," Journal of Strategic Studies, 24-4: $203-234$.

Hurrell, Andrew (2006), "The state," in Dobson, Andrew and Robyn Eckersley (ed.), Political Theory and the Ecological Challenge, Cambridge: Cambridge University Press.

Katzenstein, Peter J., Robert O. Keohane, and Stephen D. Krasner (1998), "International Organization and the Study of World Politics," International Organization, 52-4: 645-685.

Keohane, Robert O. (1988), "International Institutions: Two Approaches," International Organization, 32-4: 379-396.

Kratochwil, Friedrich (2007), "Global Governance and the Emergence of a 'World Society'," in Karagiannis, Nathalie and Peter Wagner (ed.), Varieties of World-Making: Beyond Globalization, Liverpool: Liverpool University Press.

Reus-Smit. Christian (2005), "Constructivism," in Burchill, Scott, Andrew Linklater, Richard Devetak, Jack Donnelly, Matthew Paterson, Christian Reus-Smit, and Jacqui True, Theories of International Relations, 3rd ed., Basingstoke and New York: Palgrave Macmillan.

Onuf, Nicholas (1989), World of Our Making: Rules and Rule in Social Theory and International Relations, Columbia: University of South Carolina Press.

Waltz, Kenneth N. (1979), Theory of International Politics, Boston: McGraw-Hill.

Wendt, Alexander (1992), "Anarchy is what States Make of it: The Social Construction of Power Politics," International Organization, 46-2: 391-425. 384-396.

(1994), "Collective Identity Formation and the International State," The American Political Science Review, 88-2:

(1995), “Constructing International Relation,” International Security, 20-1: 71-81.

(1999), Social Theory of International Politics, Cambridge: Cambridge University Press.

Zehfuss, Maja (2002), Constructivism in International Relations: The Politics of Reality, Cambridge: Cambridge University Press. 